\title{
Cross-shelf patterns in the community structure of coral-dwelling Crustacea in the central region of the Great Barrier Reef. II. Cryptofauna
}

\author{
Nigel P. Preston*, Peter J. Doherty** \\ School of Australian Environmental Studies, Griffith University, Nathan, Queensland 4111, Australia
}

\begin{abstract}
In a 4 yr study the crustacean cryptofaunal assemblages associated with live and dead Pocillopora verrucosa were sampled systematically from isolated coral heads placed at leeward and windward zones of an inner shelf, a mid-shelf and an outer shelf reef in the central region of the Great Barrier Reef. The spatial scales examined ranged from $1 \mathrm{~m}$ to $90 \mathrm{~km}$. At all scales there was pronounced variation in cryptofaunal abundance. Prior to bioerosion of the corals, reef location was the dominant determinant of total abundance with subordinate, taxon-specific, effects of exposure. The cryptofaunal assemblages on living and dead corals on the mid- and outer shelf reef were dominated by copepods with maximum abundance on the back reef sites of the mid-shelf reef. Total abundance was significantly lower on the inner shelf reef, which had a distinctly different assemblage characterised by fewer copepods and greater numbers of ostracods, cumaceans and tanaids. At all locations, sediment accumulated on the corals but in greater amounts on dead ones. The type of sediment trapped by corals appeared to be an important determinant of cryptofaunal composition. Over the 4 yr period, there was a significant decline in cryptofaunal abundance at all locations; this was more pronounced on dead corals and coincided with bioerosion. The results indicate that factors determining crustacean cryptofaunal abundance operate at different scales. At the cross-shelf scale, higher abundance of the predominantly copepod assemblages on the mid-shelf reef may be indicative of elevated primary productivity in this region. At the reef scale, differences in sediment composition and rates of bioerosion among zones (windward and leeward sites) may influence assemblage structure. At the replicate scale, among individual coral heads, both the abundance and composition of crustacean cryptofauna may be influenced by microhabitat features
\end{abstract}

KEY WORDS: Coral reefs · Crustacean cryptofauna $\cdot$ Community structure $\cdot$ Cross-shelf patterns

\section{INTRODUCTION}

Most coral reef habitats support abundant and diverse assemblages of small, motile crustaceans (Emery 1968, Peyrot-Clausade 1980, Klumpp et al. 1988, Lewis \& Snelgrove 1990). These assemblages are predominantly demersal forms, such as copepods and amphipods, which occupy reef habitats by day and enter the water column by night (Alldredge \& King 1977, 1980, Hobson \& Chess 1986, Jacoby \& Green-

Present addresses:

- CSIRO Marine Laboratories, PO Box 120, Cleveland, Queensland 4163, Australia

-Australian Institute of Marine Science, PMB No. 3, Townsville, Queensland 4810, Australia wood 1988), but may include more sedentary forms (Stretch 1985). These small crustaceans occupy an important position near the bottom of various food chains within the reef ecosystem, recycling detritus and coral mucus (McCloskey 1970, Richman et al. 1975, Gottfried \& Roman 1983), grazing on algae (Kensley 1984, Klumpp et al. 1988) or providing food for corals (Porter 1974). Some of this energy is transferred to higher trophic levels, as crustacean cryptofauna are a significant source of food for larger crustaceans (Reaka 1987) and many reef fishes (Hiatt \& Strasburg 1960, Hamner et al. 1988, Hobson 1991). Despite their great abundance and functional importance, our quantitative understanding of crustacean cryptofauna is poor. 
Previous ecological studies of coral reef crustacean cryptofauna have generally been focused at scales smaller than individual coral reefs, and these studies have demonstrated pronounced variation in the abundance and composition of assemblages at small spatial scales, e.g. metres or hundreds of metres (Jacoby \& Greenwood 1988). Close correlation between cryptofaunal density and algal biomass has been observed (Kensley 1984) with particularly high abundance occurring in dense patches of filamentous algae (Lobel 1980, Klumpp et al. 1988). Motile cryptofauna also vary in abundance among reef zones (Peyrot-Clausade 1980, McWilliam et al. 1981, Alldredge \& King 1977, Jacoby \& Greenwood 1988) and exhibit preferences for substrate types (De Witt 1987). A broad-scale study in the Great Barrier Reef (Riddle 1988) revealed persistent regional variations among the crustacean fauna collected from sediments of similar type.

The present study was the result of the incidental collection of crustaceans during a 4 yr project on the recruitment of juvenile coral reef fishes. In this project isolated heads of Pocillopora verrucosa coral, both living and dead, were used as recruitment traps for settling reef fish, but they also attracted large numbers of crustaceans including crabs, stomatopods, shrimps and numerous cryptofauna (Preston 1991). Since the crustaceans were efficiently collected, the design of the study provided us with the opportunity to examine regional variation in the abundance, faunal composition and replenishment of these coral associates. Previously we have reported on the agile shrimps attracted to these coral isolates (Preston \& Doherty 1990); here we focus on the smaller fauna consisting mainly of copepods, amphipods, ostracods, cumaceans, tanaids and isopods. These animals are variously described as microcrustaceans (e.g. Klumpp et al. 1988), macrofauna (e.g. Edgar 1992) or cryptofauna (e.g. PeyrotClausade 1980). In this paper, we prefer to use the term cryptofauna and thus avoid definitions based entirely on the size of fauna.

\section{MATERIALS AND METHODS}

Samples of crustacean cryptofauna were collected systematically from isolated live and dead heads of Pocillopora verrucosa that had been transplanted to sites at windward and leeward zones of 1 inner shelf, 1 mid-shelf and 1 outer shelf reef in the central region of the Great Barrier Reef (Fig. 1). On each of the 3 coral reefs, there were 6 major sampling sites: 3 sites on the back reef (leeward) and 3 sites on the front reef (windward). Adjacent sites within each exposure were separated by at least $100 \mathrm{~m}$. Within each site, there were 4 pairs of corals. Adjacent pairs were separated by 5 to

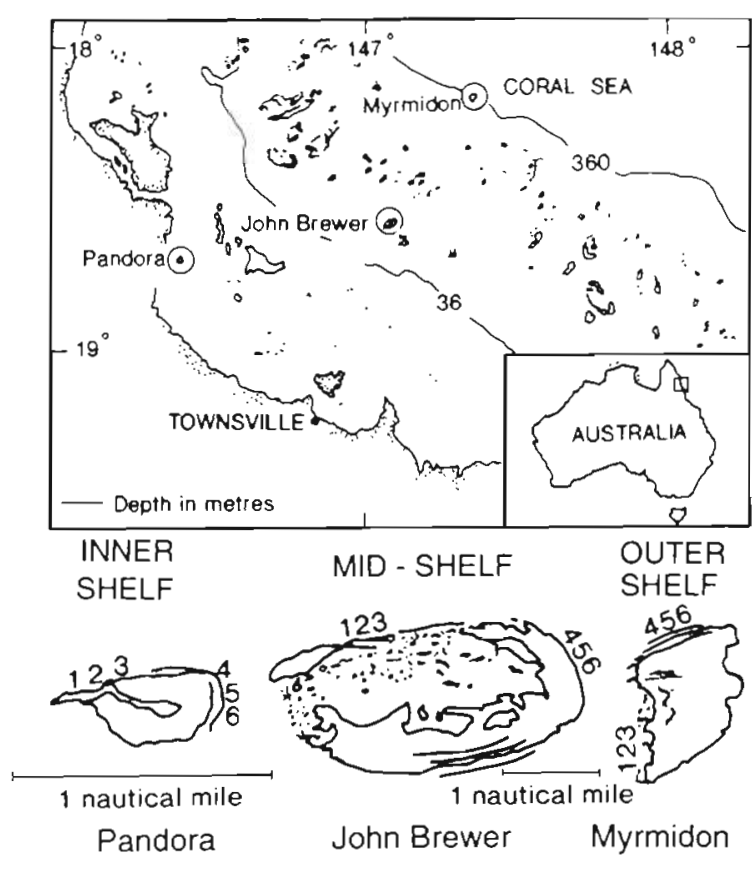

Fig. 1 Location of reefs and collection sites. Sites 1,2 \& 3: leeward (back reef); Sites 4, 5 \& 6: windward (front reef)

$10 \mathrm{~m}$, and individual coral isolates within pairs were separated by $1 \mathrm{~m}$. Each coral was set in a cement base and deployed on a star picket driven into the sand in depths of 8 to $12 \mathrm{~m}$. The corals were located at least $5 \mathrm{~m}$ from the adjacent reef slope.

Of the 4 pairs of corals constituting each site, 3 pairs were made of dead coral and 1 of living coral. All coral units were similar in size, with an approximate volume of $15000 \mathrm{~cm}^{3}$. All were made of coral collected from a single locality in the mid-shelf and transplanted to the other reefs. The cryptofauna were collected by placing a cage and plankton net (mesh size $250 \mu \mathrm{m}$ ) over the coral head. The netted corals were then inverted, brought to the surface and washed vigorously with a stream of water from an electric bilge pump. All fauna washed off the corals was immediately preserved in $10 \%$ buffered formalin. Live corals were replaced at the same site but not on the same stakes. Dead corals were returned to the ship and replaced with others in order to minimise the accumulation of fouling algae. The recently washed dead corals were kept in the sun for at least $48 \mathrm{~h}$ before being exchanged with dead corals collected from the next reef.

The sampling strategy for collecting the crustaceans varied according to the time available during the fish study. A summary of the sampling scheme for each of the 3 reefs is given in Table 1 . In the first summer, the 144 stations were each sampled 3 times: December 1982, January 1983 and February 1983. In December, 
Table 1. Summary of the number of corals sampled on each reef and the pooling procedures used. Each exposure (back reef and front reef) has 3 sites, with a total of 3 pairs of dead (D) and 1 pair of live (L) corals per site. After February 1983 there were no live corals from front reef sites (indicated by asterisks). Boxes enclosing corals within arrays denote pooling (no pooling in 1985 and 1986)

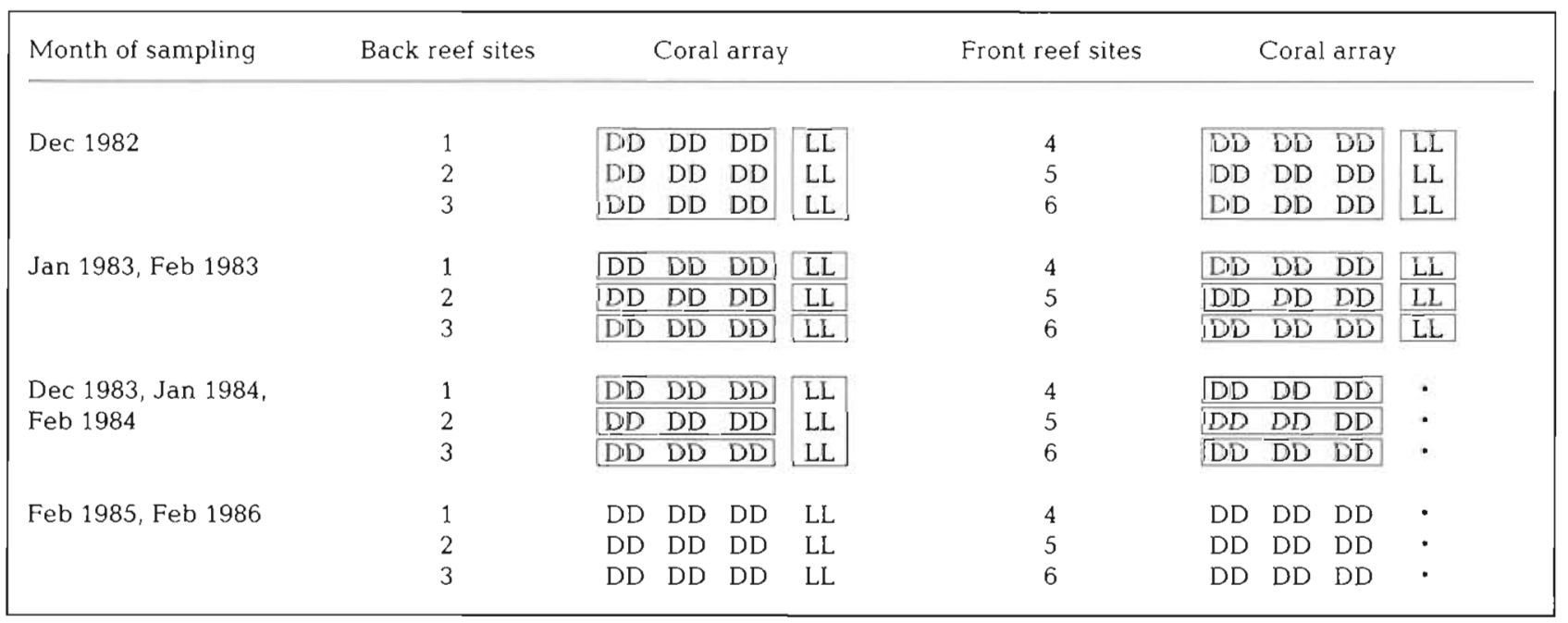

separate collections of cryptofauna were taken from live and dead corals but pooled at the level of zones. For the rest of the summer, collections were separated by substrate (live/dead) but pooled at the level of sites.

A full complement of live corals was maintained during the first summer. After the third collection, these corals were left in position while the dead corals were removed from the water to prevent fouling and bioerosion. By the start of the next summer, some of the corals that had been left on the 3 reefs had been killed by the crown-of-thorns starfish Acanthaster planci. Consequently, survivors had to be transplanted to make a full complement on the back reef sites and sampling of live corals was abandoned on the front reef sites. Cryptofauna collected from live corals in 1983-84 were pooled into single monthly collections. Dead corals were re-established on both sides of the reef. A full complement of these corals was sampled on each of the 3 reefs during the second summer and pooled into monthly collections at the level of sites.

At the end of the second summer, all corals were left in position. These corals were then sampled twice more: once in February 1985 and once in February 1986. In both these surveys, crustaceans taken from individual coral heads were maintained separately with no pooling.

After the final survey, subsets of dead corals and living corals (2 pairs of each substrate from each reef) were removed to the ship and sampled destructively in order to determine the number of crustaceans not dislodged by the washing technique.

Subsampling. In the laboratory, all crustacean samples were sorted initially by removing the larger ani- mals such as crabs, stomatopods and shrimps including their juveniles (mysids were also removed). The residue containing the smaller crustaceans together with sediment from the corals was then subsampled using a plankton wheel. The subsampling strategy varied according to previous pooling but each sample was approximately equivalent to the total fauna and sediment from a single coral head at each site. For example, in January and February 1983, the subsamples were $1 / 8$ of the total from dead corals at each site $(6$ coral heads per site) and $1 / 2$ of the total from live corals ( 2 coral heads per site). In the final 2 years $1 / 2$ of the sample was examined from each individual coral head. After subsampling the animals were sorted to the level of Order. Because we were sorting large numbers of animals of uncertain taxonomic affinity, resolution to species level was not feasible.

The relationship between the amount of sediment and the number of crustaceans was examined using a subset of the total collection. Sediment residues from all samples collected in February 1984 and 10 samples from each reef ( 5 from back reef sites and 5 from front reef sites) in February 1985 were oven-dried for $48 \mathrm{~h}$ and then weighed. The weight of sediment per coral head, estimated from pooled samples in 1984 but from individual corals in 1985, was then compared with the total number of crustaceans per coral.

Analysis of data. Because of the variable numbers of live corals and the different pooling procedures, tests for significant variation in the abundance of the major taxa among reefs, within reefs and through time could only be done using samples collected in January and February 1983. The same analysis was feasible for 
dead corals based on samples collected in January and February in 1983 and 1984. Spatial variation in numbers of total and individual taxa was examined in relation to 2 factors: reefs and zones (back reef and front reef). These factors were considered as fixed and analysed by ANOVA (Underwood 1981). The temporal stability of abundance patterns was also analysed by ANOVA. Cochran's test was used to determine the homogeneity of variances and heterogeneity was removed by $\log (x+1)$ transformations. Where significant interaction terms were detected, further analysis was done using the Student-Newman-Keuls (SNK) procedure (Winer 1971).

The data obtained from dead corals in 1985 allowed for a higher degree of spatial resolution. For these data the total number of crustaceans, obtained from the full complement of individual dead corals (108 corals), was analysed in a 4 -factor nested ANOVA (reefs, zones, sites and coral heads). Faunal similarity among and within reefs was examined by estimating dissimilarity coefficients (Bray \& Curtis 1957) for samples pooled across the first 2 years, prior to bioerosion of the corals.

\section{RESULTS}

On completion of the project, destructive sampling of 4 live corals from the front reef zone of the mid-shelf reef, following the final washing, yielded a total of
36 individuals (mostly copepods) representing about $5 \%$ of the total yield obtained previously by washing the same corals. Destructive sampling of 4 dead corals from the same reef (back reef sites) yielded 91 individuals (also mostly copepods) representing about $6 \%$ of the total. Thus the technique of vigorously washing live or dead coral heads was effective in removing most of the crustacean cryptofauna.

\section{Spatial and temporal patterns in distribution and abundance}

The distribution and abundance of the 7 most common taxa collected from live and dead corals in the first 2 summers is summarised in Table 2 . On live corals there was significant cross-shelf variation in the abundance of total cryptofauna and individual taxa (Table 3). Total abundance was highest on the front reef sites of the mid-shelf reef and lowest on the front reef sites on the outer shelf reef. As indicated by the reef by zone interaction, differences in total abundance between back and front reef sites were not consistent among reefs. Copepods were the dominant group on the midshelf and outer shelf reef, contributing between $64 \%$ and $74 \%$ of the total compared to $28 \%$ on the inner shelf reef. Gammarid amphipods were the only taxon to show an even distribution among zones and reefs. Ostracods, cumaceans and

Table 2. Mean number of crustaceans per Pocillopora verrucosa coral head in leeward (back reef) and windward (front reef) zones of 3 reefs in the central region of the Great Barrier Reef. The corals were sampled in December, January and February 1982-83 and 1983-84 except for live corals at windward (front reef) sites which were only sampled in 1982-83. n: total number of corals sampled in each zone. Standard error (of subsamples) given in parentheses

\begin{tabular}{|c|c|c|c|c|c|c|}
\hline & \multicolumn{2}{|c|}{ Inner shelf } & \multicolumn{2}{|c|}{ Mid-shelf } & \multicolumn{2}{|c|}{ Outer shelf } \\
\hline & Back reef & Front reef & Back reef & Front reef & Back reef & Front reef \\
\hline Live corals & $\mathrm{n}=36$ & $n=18$ & $\mathrm{n}=36$ & $\mathrm{n}=18$ & $\mathrm{n}=36$ & $\mathrm{n}=18$ \\
\hline Copepods & $75(14)$ & $79(5)$ & $262(65)$ & $434(80)$ & $238(37)$ & $152(16)$ \\
\hline Gammarideans & $26(3)$ & $46(5)$ & $52(5)$ & $57(3)$ & $40(4)$ & $47\{8\}$ \\
\hline Caprellids & - & - & $2(1)$ & $16(4)$ & $22(11)$ & $9(3)$ \\
\hline Ostracods & $53(7)$ & $87(10)$ & $46(5)$ & $42(3)$ & $7(2)$ & $5(2)$ \\
\hline Cumaceans & $64(12)$ & $38(3)$ & $23(6)$ & $23(3)$ & $21(8)$ & $8(1)$ \\
\hline Tanaids & $37(3)$ & $37(11)$ & $10(4)$ & $15(2)$ & $22(6)$ & $14(3)$ \\
\hline Isopods & $2(1)$ & $5(1)$ & $2(1)$ & $2(1)$ & $3(1)$ & $2(1)$ \\
\hline Total & $257(38)$ & $292(37)$ & $396(75)$ & $588(87)$ & $353(54)$ & $237(12)$ \\
\hline Dead corals & $\mathrm{n}=36$ & $n=18$ & $\mathrm{n}=36$ & $\mathrm{n}=18$ & $\mathrm{n}=36$ & $\mathrm{n}=18$ \\
\hline Copepods & $143(22)$ & $241(51)$ & 915 (268) & $1038(190)$ & $678(64)$ & $523(89)$ \\
\hline Gammarids & $86(6)$ & $184(41)$ & $196(35)$ & $219(31)$ & $84(25)$ & $118(27)$ \\
\hline Caprellids & $5(2)$ & $7(3)$ & $30(6)$ & $75(10)$ & $48(5)$ & $27(6)$ \\
\hline Ostracods & $56(20)$ & $97(21)$ & $73(17)$ & $65(15)$ & $15(2)$ & $9(2)$ \\
\hline Cumaceans & $207(25)$ & $113(21)$ & $35(5)$ & $38(7)$ & $39(7)$ & $13(2)$ \\
\hline Tanaids & $205(52)$ & $164(47)$ & $13(2)$ & $12(3)$ & $17(4)$ & $11(2)$ \\
\hline Isopods & $3(1)$ & $7(4)$ & $3(1)$ & $4(1)$ & $4(1)$ & $3(1)$ \\
\hline Total & 705 (93) & $813(173)$ & $1265(296)$ & 1451 (209) & $985(79)$ & $703(86)$ \\
\hline
\end{tabular}


Table 3. Summary of ANOVA of numbers of crustacean cryptofauna from 12 live and 36 dead Pocillopora verrucosa coral heads from each zone (windward and leeward) of 3 reefs in the central region of the Great Barrier Reef. The analysis was done on live coral samples collected in January and February 1983 and dead coral samples collected in January and February 1983 and 1984 " $p<0.05, \cdots p<0.01, \cdots p<0.001$; ns: not significant

\begin{tabular}{|c|c|c|c|c|c|c|c|}
\hline $\begin{array}{l}\text { Source of } \\
\text { variation }\end{array}$ & Total & Copepods & Gammarids & $\begin{array}{l}\text { Cryptofauna } \\
\text { Caprellids }^{a}\end{array}$ & Ostracods & Cumaceans & Tanaids \\
\hline \multicolumn{8}{|l|}{ Live corals } \\
\hline \multicolumn{8}{|l|}{ Spatial pattern } \\
\hline Reefs & $\cdots$ & $\cdots$ & ns & ns & $\cdots$ & $\cdots$ & $\cdots$ \\
\hline Zones & ns & ns & ns & $\cdots$ & ns & $\cdot$ & ns \\
\hline $\mathrm{R} \times \mathrm{Z}$ & $\cdots$ & $\cdots$ & ns & $\cdots$ & ns & ns & ns \\
\hline \multicolumn{8}{|c|}{ Temporal pattern } \\
\hline Reefs & $\cdots$ & $\cdots$ & ns & ns & . & - & ns \\
\hline Zones & ns & ns & ns & ns & ns & ns & . \\
\hline Months & $\because$ & .. & ns & ns & ns & ns & ns \\
\hline $\mathrm{R} \times \mathrm{Z}$ & ns & ns & ns & - & ns & ns & ns \\
\hline$R \times M$ & ns & ns & ns & - & ns & ns & $\cdot$ \\
\hline $\mathrm{Z} \times \mathrm{M}$ & ns & ns & ns & ns & ns & ns & ns \\
\hline $\mathrm{R} \times \mathrm{Z} \times \mathrm{M}$ & ns & $\cdot$ & ns & ns & ns & ns & ns \\
\hline \multicolumn{8}{|l|}{ Dead corals } \\
\hline \multicolumn{8}{|l|}{ Spatial pattern } \\
\hline Reefs & - & $\cdots$ & ns & $\cdots$ & $\cdots$ & $\cdots$ & $\cdots$ \\
\hline Zones & ns & ns & ns & $\cdots$ & ns & $\cdots$ & ns \\
\hline $\mathrm{R} \times \mathrm{Z}$ & ns & ns & $\cdots$ & $\cdots$ & ns & $\cdots$ & ns \\
\hline \multicolumn{8}{|c|}{ Temporal pattern } \\
\hline Reefs & ns & . & ns & . & ns & - & . \\
\hline Zones & ns & - & ns & ns & ns & ns & ns \\
\hline Years & ns & ns & ns & ns & ns & ns & ns \\
\hline Months (Y) & $\cdots$ & $\cdots$ & • & ns & ns & • & $\cdots$ \\
\hline $\mathrm{R} \times \mathrm{Z}$ & ns & ns & ns & ns & ns & ns & ns \\
\hline$R \times Y$ & ns & ns & ns & ns & - & ns & ns \\
\hline $\mathrm{R} \times \mathrm{M}(\mathrm{Y})$ & $\cdots$ & $\cdots$ & ns & ns & ns & ns & ns \\
\hline $\mathrm{Z} \times \mathrm{Y}$ & ns & ns & ns & ns & ns & ns & ns \\
\hline $\mathrm{Z} \times \mathrm{M}(\mathrm{Y})$ & ns & ns & ns & ns & ns & ns & ns \\
\hline $\mathrm{R} \times \mathrm{Z} \times \mathrm{Y}$ & ns & ns & ns & ns & ns & ns & ns \\
\hline$R \times Z \times M(Y)$ & ns & - & ns & ns & ns & $\cdots$ & ns \\
\hline
\end{tabular}

tanaids were all significantly more abundant on the inner shelf reef than on the other reefs. Among this group, only cumaceans showed significant variation between zones, with greater abundance on back reef sites than on front reef sites at the inner and outer shelf reefs.

There was a generally persistent cross-shelf pattern in the temporal variation of cryptofaunal abundance on live corals. The mid-shelf reef consistently yielded greater total numbers, dominated by copepods, but with significant monthly variation in the pattern of replenishment of copepods among zones within reefs. Gammarid amphipods, ostracods and cumaceans all showed a regular pattern of monthly replenishment, with no significant variation in abundance between months, among reefs or between zones. The monthly pattern of replenishment of the least abundant taxa, tanaids and caprellid amphipods, varied among reefs in that there was no consistent zone effect.

At all locations, dead corals yielded approximately 3 times as many crustaceans as did live corals from the same sites (Table 2). The spatial pattern in total cryptofaunal abundance was similar to that on live corals, with greater abundance on the mid-shelf reef than on the inner or outer shelf reef. The cross-shelf distribution of taxa was also similar to that on live corals except that, on dead corals, cumaceans and tanaids were relatively more abundant on the inner shelf reef.

The pattern of monthly variation in total cryptofaunal abundance on dead corals was consistent among reefs and zones and between years (Table 3 ). Copepod abundance was more variable than on live corals with no consistent pattern of replenishment among zones. Taxa of intermediate abundance, the cumaceans and 
tanaids, were persistently more abundant on the inner shelf reef, whereas the least abundant taxon, caprellid amphipods, were persistently more abundant on the mid-shelf and outer shelf reef.

\section{Faunal similarity among reeis}

Comparison of faunal similarity among reefs showed that, irrespective of substrate type (living or dead coral), there was a distinct separation between the faunal composition on the inner shelf and that on the midshelf and outer shelf reefs (Fig. 2). At the lower levels of separation, differences in the faunal composition between zones were most pronounced on the inner shelf reef for both living and dead corals.

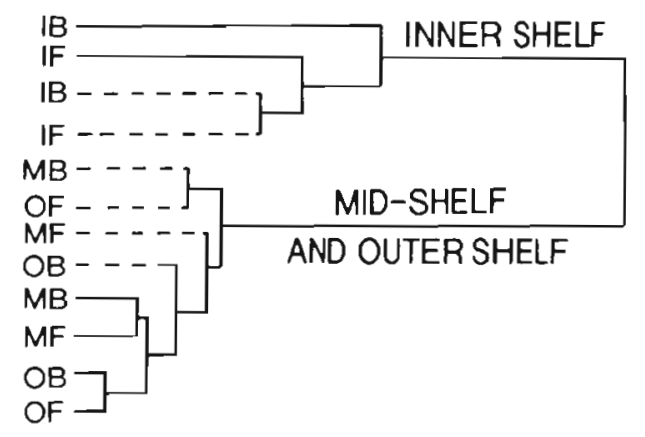

Fig. 2. Cross-shelf pattern of faunal similarity of crustacean cryptofauna from living and dead Pocillopora verrucosa corals based on pooled samples from January and February 1984. $\mathrm{I}=$ inner shelf, $\mathrm{M}=$ mid-shelf $\mathrm{O}=$ outer shelf reef. $\mathrm{B}=$ back reef, $F=$ front reef. Dashed lines denote samples from live corals

\section{Longer-term trends}

In the last 2 summers (February 1985 and February 1986), during which single surveys were done, the fate of the transplanted live corals differed among locations. On the inner shelf reef, all the live corals on the back reef sites survived in a healthy state. Total cryptofaunal abundance was comparable to values recorded in previous years (Fig. 3) with little change in community structure (Fig. 4). On the mid-shelf reef, all live corals showed a marked reduction in size and some were completely destroyed by Acanthaster planci in 1985, or Cyclone Winifred in 1986. Total cryptofaunal abundance on the remaining live corals was within the range observed in previous years. However, there were pronounced changes in the community structure

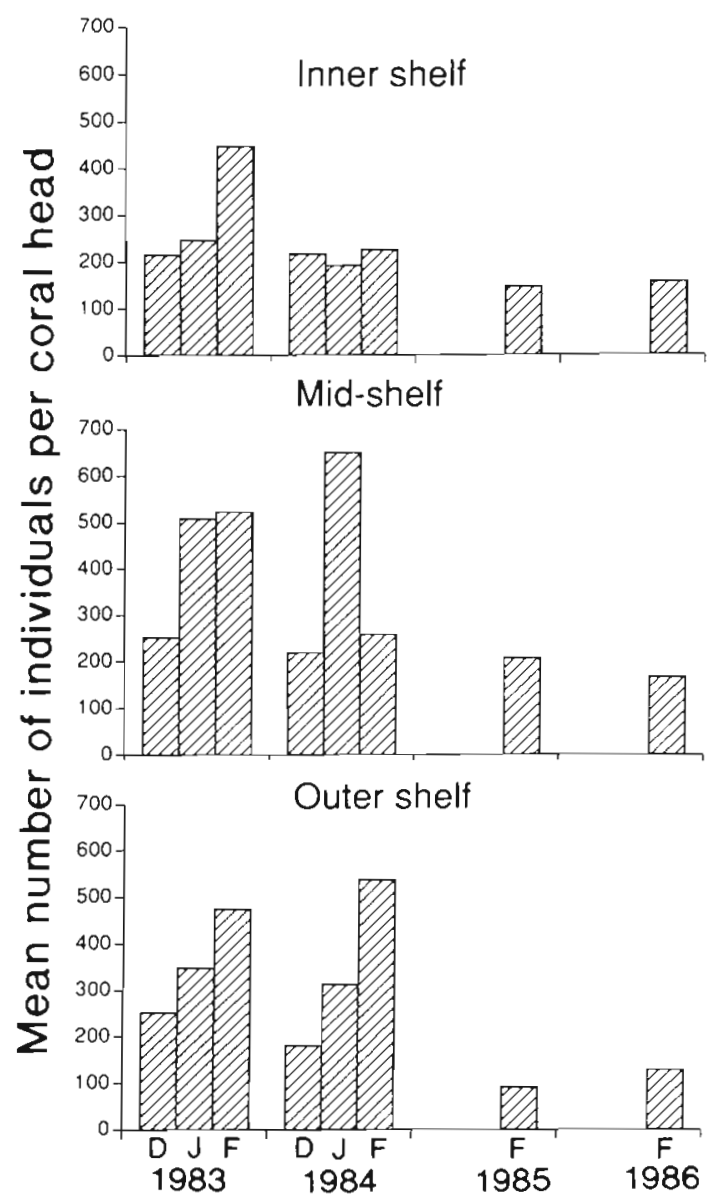

Fig. 3. Cross-shelf pattern of temporal variation in mean abundance of total crustacean cryptofauna per live Pocillopora verrucosa coral head from back reef (leeward) sites

with a marked reduction in the relative abundance of copepods and marked increase in the relative abundance of ostracods. On the outer shelf reef, some of the corals were destroyed but those remaining appeared healthy. Cryptofaunal abundance was lower than in previous years and community structure showed similar changes to those observed on the mid-shelf reef.

At all locations, the dead corals were eroded during the lengthy intervals between the 2 final samplings. By February 1985, the size of dead corals at all locations was reduced by 10 to $15 \%$ and many of the corals were fouled by filamentous algal growths. At all locations, reduction in the size of corals was accompanied by a pronounced reduction in the mean numbers of total crustacean cryptofauna (Fig, 5). Despite the substantial decline in cryptofaunal abundance, we analysed the data obtained from individual coral heads in 1985 to examine small-scale 

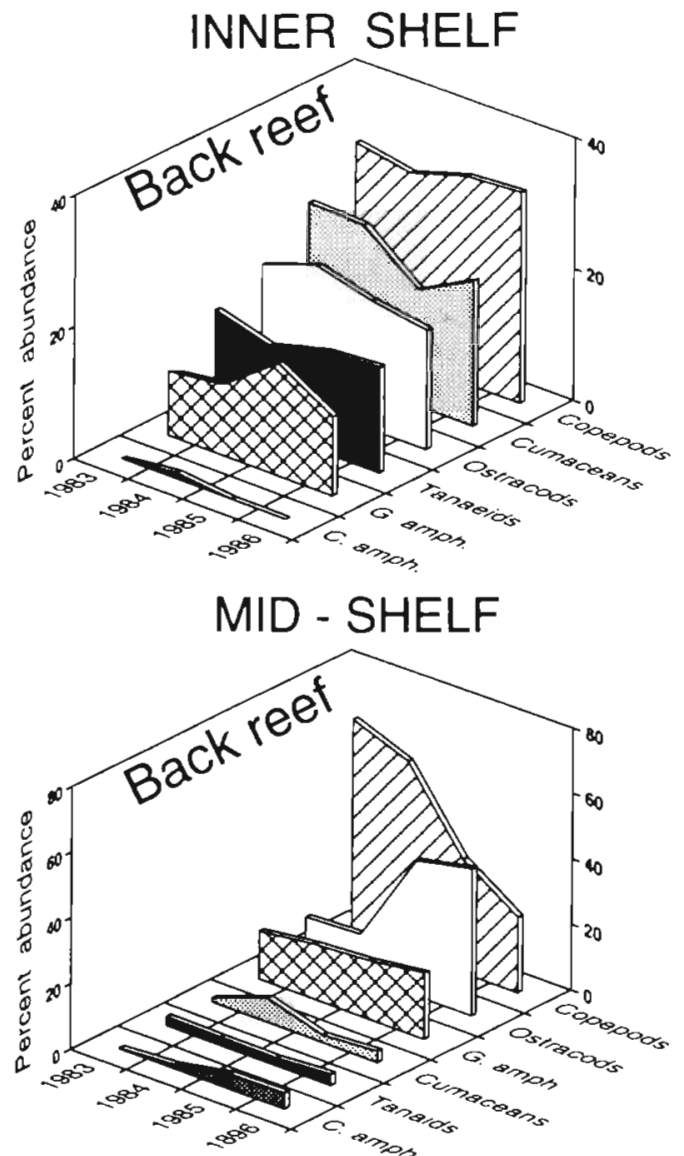

\section{OUTER SHELF}

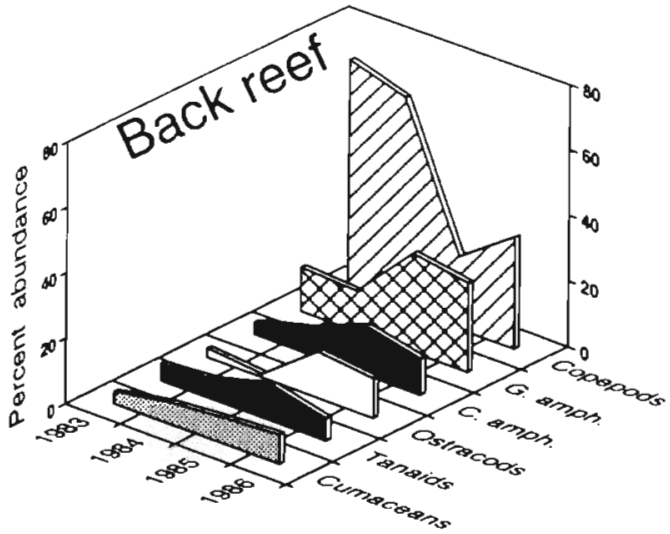

Fig. 4. Cross-shelf pattern of inter-annual variations in the relative abundance of crustacean cryptofauna from live Pocillopora verrucosa coral heads from back reef sites of 3 coral reefs. G. amph. = gammarid amphipods; $\mathrm{C}$. amph. = caprellid amphipods

variation in total abundance. The results showed little evidence of the differences among reefs detected in previous years. Furthermore, the factor 'Reefs' accounted for only $4 \%$ of the total variation (Table 4). Differences in abundance between zones

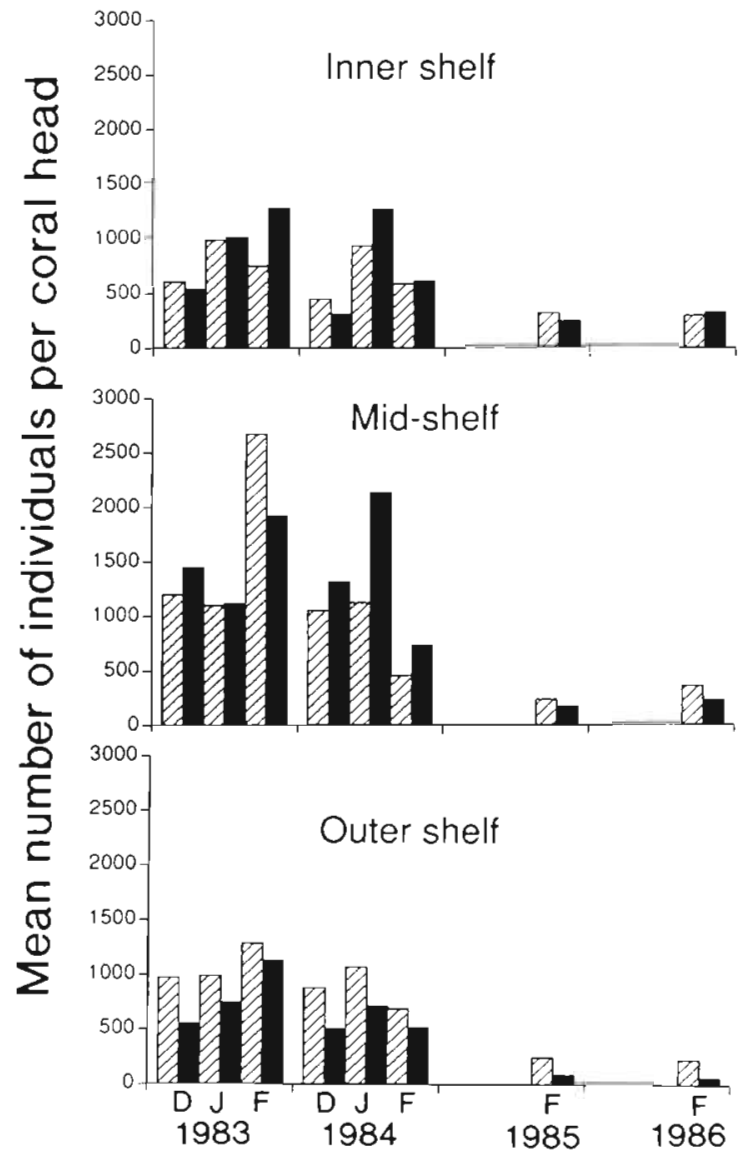

Fig. 5. Cross-shelf pattern of temporal variation in mean abundance of total crustacean cryptofauna per dead Pocillopora verrucosa coral head from back reef sites (hatched bars) and front reef sites (solid bars)

were significant and contributed $33 \%$ of the total variation. Individual sites $(20 \%)$ and coral heads $(10 \%)$ also accounted for significant levels of the total variation.

Erosion of the dead corals resulted in a pronounced change in the pattern of relative abundance of the cryptofauna. On the inner shelf reef, the changes in community structure were not consistent between zones (Fig. 6). On back reef sites there was a marked reduction in the relative abundance of the previously dominant tanaids and cumaceans and a concomitant increase in gammaridean amphipods and ostracods. On front reef sites cumaceans and ostracods showed the same trends but there was no decline in the relative abundance of tanaids or increase in gammaridean amphipods. At all other locations, there were consistent changes in cryptofaunal community structure in response to the erosion of the dead corals. Cope- 
Table 4. Nested ANOVA of the abundance of total crustacean cryptofauna on isolated heads of dead Pocillopora verrucosa coral from leeward and windward zones on 3 reefs in the central region of the Great Barrier Reef in February 1985. $\mathrm{n}=18$ in each zone. $\cdots p<0.01, \cdots p<0.001 ;$ ns: not significant

\begin{tabular}{|lcrcccr|}
\hline Source & SS & df & MS & $F$ & $p$ & \% Var. \\
\hline Reefs & 67279 & 2 & 33639 & 1.2 & ns & 3.8 \\
Zones & 79626 & 3 & 26542 & 4.4 & $\ldots$ & 32.4 \\
Sites & 72609 & 12 & 6050 & 3.2 & $\cdots$ & 19.7 \\
Coral heads $(\mathrm{R}, \mathrm{Z}, \mathrm{S})$ & 68510 & 36 & 1903 & 1.6 & $\cdots$ & 10.1 \\
Residual & 64602 & 54 & 1196 & - & - & 34.1 \\
\hline
\end{tabular}

pods, which dominated the cryptofauna on the midshelf and outer shelf reef in the first 2 summers, showed a pronounced decline in abundance. Conversely, all other taxa, particularly the gammaridean amphipods and ostracods, increased in relative abundance.

\section{Sediment/fauna relationships}

The different amount of sediment in the samples demonstrated that live corals accumulate or retain less sediment than dead ones (Table 5). There was considerable variation in sediment weight among individual living or dead coral isolates. Comparison of the mean weight of sediment per coral head indicated that location or year had little influence on the amount of sedi-

Table 5. Summary of the estimated mean weight of sediment and mean number of crustaceans per coral head from 1 inner shelf reef, $1 \mathrm{mid}$-shelf reef and 1 outer shelf reef in the central region of the Great Barrier Reef. In $1984 \mathrm{n}=18$ for dead corals and $n=9$ for live corals on each reef. In $1985 n=5$ for dead corals and live corals on each reef. SD in parentheses

\begin{tabular}{|lcc|}
\hline $\begin{array}{l}\text { Substrate, year } \\
\text { and location }\end{array}$ & $\begin{array}{c}\text { g sediment } \\
\text { per coral head }\end{array}$ & $\begin{array}{c}\text { No. of crustaceans } \\
g^{-1} \text { sediment }\end{array}$ \\
\hline $\begin{array}{l}\text { Dead corals } \\
\text { 1984, Inner shelf }\end{array}$ & $5.4(0.5)$ & $107(6.5)$ \\
1985, Inner shelf & $5.3(2.1)$ & $32(3.8)$ \\
1984, Mid-shelf & $5.2(2.1)$ & $151(39)$ \\
1985, Mid-shelf & $6.9(1.8)$ & $20(2.8)$ \\
1984, Outer shelf & $7.2(3.1)$ & $153(46.1)$ \\
1985, Outer shelf & $6.4(1.5)$ & $30(5.6)$ \\
& & \\
Live corals & 1.4 & 143 \\
1984, Inner shelf & 1.3 & 68 \\
1985, Inner shelf & 2.7 & 164 \\
1984, Mid-shelf & 3.3 & 74 \\
1985, Mid-shelf & 3.1 & 78 \\
1984, Outer shelf & 3.6 & \\
1985, Outer shelf & & \\
\hline
\end{tabular}

ment accumulated by living or dead corals. Regression analysis demonstrated that, at all locations and for both live and dead coral substrates, there was no significant relationship between sediment weight and the total numbers of cryptofauna. The decline in total numbers of cryptofauna observed in the last 2 summers was therefore assumed to be independent of the amount of sediment retained by the eroding corals.

\section{DISCUSSION}

The crustacean cryptofauna collected from the coral isolates used in this study were predominantly transitory occupants of reef substrates. Previous studies have established that assemblages of these animals are characterised by rapid turnover and redistribution via nightly migration into the water column (e.g. Alldredge \& King 1977, 1980, Jacoby \& Greenwood 1988). Our results have shown that daytime defaunation of coral isolates is an effective technique for obtaining quantitative estimates of these assemblages. Sampling directly from naturally occurring substrates circumvents many of the problems encountered with emergence or re-entry traps (Hobsen \& Chess 1979, Alldredge \& King 1980, Stretch 1985). Standardising the sampling units also removes some of the uncertainty concerning the relative importance of factors such as reef location (Gotelli et al. 1985), coral host size (Austin et al. 1980) or coral structure (Lewis \& Snelgrove 1990).

In the first 2 years of this study, cryptofaunal abundance was persistently greater on the mid-shelf reef due to large numbers of copepods. We did not examine species composition in detail but the copepods were predominantly demersal species and the majority of these were harpacticoids, including examples from the Peltidiidae and Thalestridae. Other non-harpacticoid copeods that were represented included species of Eucalanus, Acartia and Lucicutia. The composition of the crustacean cryptofauna in our samples was more similar to that captured in sealed traps by Hobson \& Chess (1979) than that captured in the more open design of trap used by Alldredge \& King (1977). This indicates that contamination of our samples with holoplankton was slight

Two previous studies have examined the cross-shelf distribution and abundance of zooplankton in the central region of the Great Barrier Reef (Sammarco \& Crenshaw 1984, Williams et al. 1988). Neither study spanned the entire continental shelf and both were concerned with holoplankton rather than demersal 

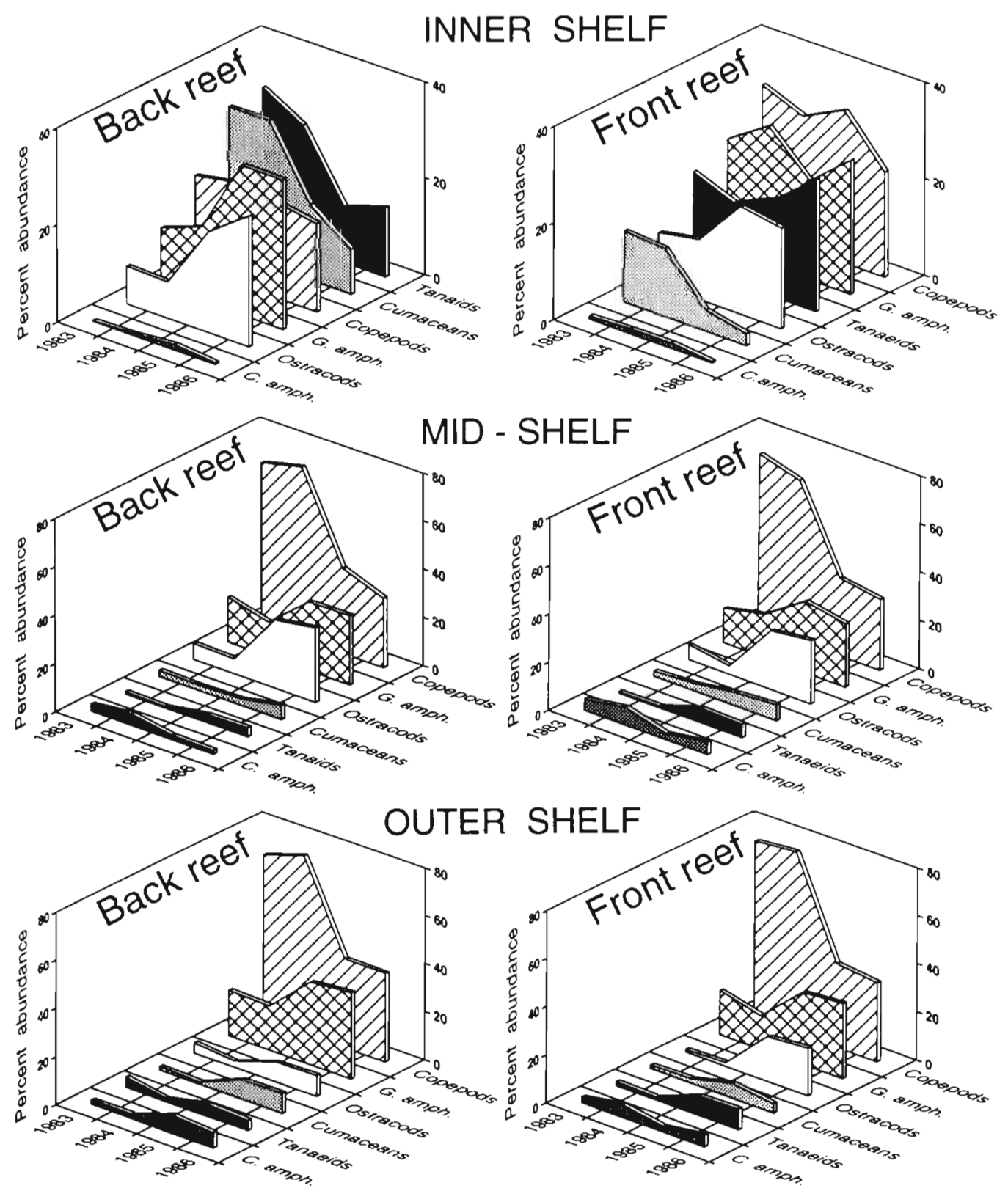

Fig. 6. Cross-shelf patterns of inter-annual variations in the relative abundance of crustacean cryptofauna from dead Pocillopora verrucosa coral heads from back reef and front reef sites of 3 coral reefs. Abbreviations as in Fig. 4

animals. Sammarco \& Crenshaw (1984) sampled stations along a transect extending from the inner shelf region to the mid-shelf region. Zooplankton abundance appeared to be strongly influenced by terrigenous runoff with peaks in abundance occurring close to land, particularly at times of peak river discharge. In the present study we found no evidence of a progressive shoreward increase in demersal zooplankton abundance to parallel that reported for holoplanktonic animals.
Williams et al. (1988) sampled a transect extending from the mid-shelf to the outer shelf. Their study indicated that the total density of copepods was greater in the mid-shelf region than in the outer shelf region. A possible link between the upwelling of nutrient-rich water and greater biomass of zooplankton around the mid-shelf reefs has been suggested (Williams \& Hatcher 1983, Furnas \& Mitchell 1986, 1987). The relatively high cryptofaunal abundance that we observed on the mid-shelf reef is consistent with the concept of 
greater nutrient input to this region (Andrews \& Gentien 1982). However, further work is needed to determine the impacts of regional variation in nutrient input on demersal reef zooplankton.

At all the reefs that we surveyed, sediment accumulated on the coral isolates although in greater amounts on dead corals than on living corals. The sediment composition and infauna from the same cross-shelf transect has previously been examined by Riddle (1988). Overall the patterns of distribution of the fauna that we collected from coral isolates were similar to those recorded by Riddle. Location was the dominant factor with subordinate effects of exposure (front and back reef) and substrate (living or dead coral). However, our results underscore the advice of Jacoby \& Greenwood (1988) on the need for caution when generalising about the factors that generate or sustain such patterns. For example, Riddle (1988) suggested that the virtual absence of amphipods, and other peracarids, from the sediments of the outer shelf reef indicated a barrier to recruitment of benthic animals, such as amphipods, that lack planktonic larvae. We found no evidence that amphipods were less abundant on the coral isolates on the outer shelf reef; in fact, gammarid amphipods were the only taxon with no significant cross-shelf difference in abundance on either living or dead isolates. Cross-shelf variation in the occurrence of amphipod species with different habitat preferences seems the most likely explanation for these contrasting results. Variation in microhabitat selection has been demonstrated among amphipod species (Edgar 1992) and age classes (DeWitt 1987).

The types of sediments that accumulated on coral isolates and the regional variation in their composition showed the same general characteristics as the sediment core samples described by Riddle (1988). Sediments from coral isolates transplanted to the inner shelf contained more clay/mud and organic matter than those at the mid-shelf or outer shelf. The relatively high sediment organic load at the inner shelf region may account for the presence of significantly greater numbers of deposit feeders, such as tanaids, cumaceans and ostracods, compared to other locations. Smaller-scale, within-reef patterns may also be influenced by sediment types. For example, the relatively high abundance of cumaceans on the back reef sites of the inner shelf reef may be due to the higher levels of silt/clay and organic carbon than on the front reef sites

Previous estimates of demersal reef zooplankton abundance using emergence traps have indicated that greater numbers emerge from living corals than from dead corals (Alldredge \& King 1977). In contrast to this, our results showed that, prior to bioerosion, the dead corals at all locations yielded about 3 times as many crustaceans as did live corals from the same sites. As suggested by Jacoby \& Greenwood (1988), some demersal zooplankton that appear to be associated with live coral may in fact emerge from the sand at the base of the coral. In the present study we did not attempt to determine what proportion of the live coral cryptofauna resided in the dead coral base or sediment. We did find that, within locations, there was a high degree of cryptofaunal similarity between living and dead corals.

Increased faunal abundance on dead corals may have been, in part, due to the accumulation of more sediment than on living coral. However, the loss of dead coral branches due to bioerosion resulted in a dramatic decline in faunal abundance despite only minor changes in the amount of sediment trapped by the corals. This effect was more pronounced on dead corals than the living corals, many of which remained in a healthy state. We conclude from this comparison that, in general, the living branches of Pocillopora verrucosa were less attractive to crustacean cryptofauna than dead corals.

Coral skeletons are colonised by filamentous algae and other epiphytes which provide a greater diversity of microhabitats than those available on living coral. Previous studies have demonstrated that cryptofaunal abundance on dead coral is closely correlated with the density of filamentous algae (Lobel 1980, Klumpp et al. 1988). In the first 2 years of our study the accumulation of epiphytes was retarded by drying the corals in the sun at each monthly changeover. It is, however, likely that epiphytic growth in the monthly sampling intervals increased the attractiveness of the dead corals and provided a source of food for micrograzers such as amphipods (Brawley \& Adey 1981). Experimental manipulation has demonstrated that seagrass cryptofaunal abundance responds rapidly to fine-scale variation in microhabitat composition or structure (Edgar 1992) and these factors need to be examined in greater detail within coral reef ecosystems.

Coral skeletons are eventually penetrated by boring organisms and eroded away at rates that differ between reef environments (Coles 1980, Hutchings et al. 1992). Increased cryptofaunal abundance due to epiphytic growth may, therefore, be balanced by the loss of habitat due to bioerosion. In the final 2 years of this study, the dead corals were immersed for lengthy periods ( 9 and $12 \mathrm{mo}$ ) between sampling and the size of the corals was reduced by 10 to $15 \%$ but much of the remaining substrate was fouled by luxuriant growth of filamentous algae. An apparent response to these changes was a dramatic decline in copepod abundance, particularly at the mid-shelf reef and outer shelf reef which initially supported the greatest num- 
bers of copepods. Klumpp et al. (1988) reported increased abundance of copepods, mainly harpacticoids of the families Peltidiidae and Thaelestridae, in dense patches of filamentous algae inside damselfish Stegastes apicalis territories. These families of harpacticoids were well represented in the copepod samples we collected in the first 2 years but, as with all the copepods, declined in abundance over the last 2 years despite the increased algal biomass. Analysis of cryptofaunal densities on eroded coral skeletons revealed significantly lower abundance on the exposed sites at all locations. We did not determine whether bioerosion rates varied among zones but Hutchings et al. (1992) have shown that bioerosion rates are related to exposure.

Long-term trends in cryptofaunal abundance and composition on living corals were similar to those on coral skeletons. On the mid-shelf and outer shelf, which initially supported the greatest number of copepods, there was a pronounced change in faunal composition due mainly to a decline in copepod abundance. Many of the live corals on these reefs suffered damage due to Acanthaster planci in 1985 or Cyclone Winifred in 1986. The decrease in copepod numbers seems disproportionate to the amount of habitat lost through bioerosion, which suggest that factors other than habitat size alone contribute to copepod abundance. Lewis \& Snelgrove (1990) have demonstrated that crustacean cryptofaunal abundance responds to different growth forms of the hermatypic coral Madracis mirabilis. Fewer copepods were found on corals with short, widely separated branches than on those with long, thin, tightly spaced branches. Our results also indicate that the processes that affect the abundances of different taxa may vary according to the microhabitats occupied within branching corals. In particular, copepods appear to be more sensitive to loss of branching structure on both living and dead corals.

The pronounced cross-shelf variation in cryptofaunal composition that we observed at the high taxonomic level of Order is likely to be considerably amplified at the level of Species. Further broad-scale studies focused on individual species and their sources of nutrition are required in order to elucidate some of the underlying processes that give rise to, maintain or modify cross-shelf patterns in the abundance and composition of crustacean cryptofauna.

Acknowledgements. Funds were received from AMSTAC grant 84/1872 and AIMS. The crew of the 'Harry Messel' and numerous volunteer divers assisted with sample collection. D. Tafe advised on taxonomy, M. J. Riddle and 2 anonymous reviewers improved the manuscript; our thanks to all.

\section{LITERATURE CITED}

Alldredge, A. L., King J. M. (1977). Distribution, abundance, and substrate preferences of demersal reef zooplankton at Lizard Island Lagoon, Great Barrier Reef. Mar. Biol. 41. $317-333$

Alldredge, A. L., King J. M. (1980). Effects of moonlight on the vertical migration patterns of demersal zooplankton. J. exp. mar. Biol. Ecol. 44: 133-156

Andrews, J. C., Gentien, P. (1982). Upwelling as a source of nutrients for the Great Barrier Reef ecosystems: a solution to Darwin's question? Mar. Ecol. Prog. Ser. 8 : $257-269$

Austin, A. D., Austin, S. A., Sale, P. F. (1980). Community structure of the fauna associated with the coral Pocillopora damicornis (L.) on the Great Barrier Reef. Aust. J. mar. Freshwat. Res. 31: 163-174

Brawley, S. H., Adey, W. H. (1981). The effect of micrograzers on algal community structure in a coral reef microcosm. Mar. Biol. 61: 167-179

Bray, J. R., Curtis, J. T. (1957). An ordination of the upland forest communities of southern Wisconsin. Ecol. Monogr. 27 : $325-349$

Coles, S. L. (1980). Species diversity of decapods associated with living and dead reef coral Pocillopora meandrina. Mar. Ecol. Prog. Ser. 2: 281-291.

DeWitt, T H. (1987). Microhabitat selection and colonisation rates of a benthic amphipod. Mar. Ecol. Prog. Ser. 36: $237-250$

Edgar, G. J. (1992). Patterns of colonisation of mobile epifauna in a Western Australian seagrass bed. J. exp. mar. Biol. Ecol. 157: 225-246

Emery, A. R. (1968). Preliminary observations on coral reef plankton. Limnol. Oceanogr. 13: 293-303

Furnas, M. J., Mitchell, A. W. (1986). Phytoplankton dynamics in the Central Great Barrier Reef. 1. Seasonal changes in biomass and community structure and their relation to intrusive activity. Contin. Shelf. Res. 6: 363-384

Furnas, M. J., Mitchell, A. W. (1987). Phytoplankton dynamics in the Central Great Barrier Reef. 11. Primary production. Contin. Shelf. Res. 7: 1049-1062

Gotelli, N. L., Gilchrist, S. L., Able, L. G. (1985). Population biology of Trapezia spp. and other coral associated decapods. Mar. Ecol. Prog. Ser. 21: 89-98

Gottfried, M., Roman, M. R. (1983). Ingestion and incorporation of coral-mucus detritus by reef zooplankton. Mar. Biol. 72: 211-218

Hamner, W. M., Jones, M. S., Carleton, J. H., Hauri, I. R., McB. Williams, D. (1988). Zooplankton, planktivorous fish, and water currents on a windward reef face: Great Barrier Reef, Australia. Bull. mar. Sci. 42(3): 459-479

Hiatt, W., Strasburg, D. (1960). Ecological relationships of the fish fauna on coral reefs of the Marshall Islands. Ecol. Monogr. 30: 65-127

Hobson, E. S. (1991). Trophic relationships of fishes specialized to feed on zooplankters above coral reefs. In: Sale, P. F. (ed.) The ecology of fishes on coral reefs. Academic Press, New York, p. 69-95

Hobson, E. S., Chess, J. R. (1979). Zooplankton that emerge from the lagoon floor at night at Kure and Midway Atolls, Hawaii. Fish. Bull. U.S. 77: 275-280

Hobson, E. S., Chess, J. R. (1986). Diel movements of resident and transient zooplankters above reefs at Enewetak Atoll, Marshall Islands. Pacif. Sci. 40: 7-26

Hutchings, P. A., Kiene, W. E., Cunningharn, R. B., Donnelly, C. (1992). Spatial and temporal patterns of non-colonial boring organisms (polychaetes, sipunculans and bivalve 
molluscs) in Porites at Lizard Island, Great Barrier Reef. Coral Reefs 11: $23-31$

Jacoby, C. A., Greenwood, J. G (1988). Spatial, temporal, and behavioral patterns in emergence of zooplankton in the Lagoon of Heron Reef, Great Barrier Reef, Australia. Mar. Biol. 97: 309-328

Kensley, B. (1984). The role of isopod crustaceans in the reef crest community at Carrie Bow Cay, Belize, P.S.Z.N. I: Mar. Ecol. 5: 29-44

Klumpp, D. W., McKinnon, A. D., Mundy, C. N. (1988). Motile cryptofauna of a coral reef: abundance, distribution and trophic potential. Mar. Ecol. Prog. Ser. 45: 95-108

Lewis, J. B., Snelgrove, P. V. R. (1990). Corallum morphology and composition of crustacean cryptofauna of the hermatypic coral Madracis mirabilis. Mar. Biol. 106: 267-272

Lobel, P. S. (1980). Herbivory by damselfishes and their role in coral reef community ecology. Bull. mar. Sci. 30: 273-289

McCloskey, L. R. (1970). The dynamics of the community associated with a marine scleractinian coral. Int. Revue ges. Hydrobiol. 55: 13-81

McWilliam, P. S., Sale, P. F., Anderson, D. T. (1981). Seasonal changes in resident zooplankton sampled by emergence traps in One Tree Lagoon Great Barrier Reef. J. exp. mar. Biol. Ecol. 52: 185-203

Peyrot-Clausade, M. (1980). Motile cryptofauna of Tulear Reef Flats. Mar. Biol. 59: 43-47

Porter, J W. (1974). Zooplankton feeding by the Caribbean reef-building coral Montastrea cavernosa. Proc. 2nd int. coral Reef Symp. 1. 111-125

Preston, N. P. (1991). Replenishment of crustacean associates of coral isolates in the central region of the Great Barrier Reef. Mem. Qld Mus. 31: 398

This article was submitted to the editor
Preston, N. P., Doherty, P. J. (1990). Cross-shelf patterns in the community structure of coral-dwelling Crustacea in the central region of the Great Barrier Reef. I. Agile shrimps. Mar. Ecol. Prog. Ser. 66: 47-61

Reaka, M. L. (1987). Adult-juvenile interactions in benthic reef crustaceans. Bull. mar. Sci. 41(2): 108-134

Richman, S., Loya, Y., Slobodkin, L. B. (1975). The rate of mucus production by corals and its assimilation by the coral reef copepod Acartia negligens. Limnol. Oceanogr. 20(6): $918-923$

Riddle, M. J. (1988). Patterns in the distribution of macrofaunal communities in coral reef sediments on the central Great Barrier Reef. Mar. Ecol. Prog. Ser. 47: 281-292

Sammarco, P. W., Crenshaw, H. (1984). Plankton community dynamics of the central Great Barrier Reef Lagoon: analysis of data from Ikeda et al. Mar. Biol. 82: 167-180

Stretch, J. S. (1985). Quantitative sampling of demersal zooplankton: reentry and airlift dredge sample comparisons. J. exp. mar. Biol. Ecol. 91: 125-136

Underwood, A. J. (1981). Techniques of analysis of variance in experimental marine biology and ecology. Oceanogr. mar. Biol. A. Rev. 19: 513-605

Williams, D. McB., Dixon, P., English, S. (1988). Cross-shelf distribution of copepods and fish larvae across the central Great Barrier Reef. Mar. Biol. 99: 577-589

Williams, D. McB., Hatcher, A. I. (1983). Structure of fish communities on outer slopes of inshore, mid-shelf and outer shelf reefs of the Great Barrier Reef. Mar. Ecol. Prog. Ser. 10: $239-250$

Winer, B. J. (1971). Statistical principles in experimental design, 2nd edn. McGraw-Hill, Kogskusha, Tokyo

Manuscript first received: May 14, 1993

Revised version accepted: October 20,1993 